\title{
Lung metastases of ameloblastic carcinoma 10 years after primary hemimandibulectomy: A case report
}

\author{
Zulkifli Amin ${ }^{1}$, Sunhadji Rubangi², Catharina Rini Suprapti ${ }^{3}$
}

1 Division of Pulmonology, Department of Internal Medicine, Faculty of Medicine, University of Indonesia/Dr. Cipto Mangunkusumo Hospital, Jakarta, Indonesia

2 Division of Thoracic Surgery, Department of Surgery Faculty of Medicine, University of Indonesia/Dr. Cipto Mangunkusumo Hospital, Jakarta, Indonesia

3 Division of Oral and Maxillofacial Surgery, Department of Oral Disease, Faculty of Medicine, University of Indonesia/Dr. Cipto Mangunkusumo Hospital, Jakarta, Indonesia

\begin{abstract}
Abstrak
Ameloblastoma merupakan jenis tumor odontogenik yang umumnya jinak. Namun demikian, kurang dari 2\% kasus ameloblastoma mengalami metastasis, terutama ke paru. Kami melaporkan satu kasus ameloblastik karsinoma dengan metastasis di kedua paru setelah 10 tahun pasca reseksi tumor primer dan 2 tahun pasca kemoterapi.
\end{abstract}

(Med J Indones 2009; 18: 60-3)

\begin{abstract}
Ameloblastoma is a type of odontogenic tumor and generally considered as a benign tumor. However, less than $2 \%$ of ameloblastoma were found to have metastases, mostly to the lung. We reported a case of 46-year-old man presenting with an ameloblastic carcinoma with lung metastases 10 years after the primary tumor was resected and 2 years after chemotherapy. (Med J Indones 2009; 18: 60-3)
\end{abstract}

Keywords: ameloblastoma, chemotherapy, radiation

Ameloblastomas represent $1 \%$ of all jaw tumors. They generally are regarded as benign tumors; however, more than half of the resected tumors recur. Therefore they are considered as locally malignant but not metastasizing. Metastases, however, are known to occur in roughly 2 to $5 \%$ of cases. More than $80 \%$ of such metastases involve the lung. ${ }^{1,2}$ A retrospective study of 1642 cases in a Chinese population found that ameloblastoma was the most common type (40.3\%) of odontogenic tumors. Most of these tumors were benign, but $1.6 \%$ was found to be malignant (ameloblastic carcinoma). ${ }^{3}$

In this case report we described a case of an ameloblastic carcinoma with lung metastases 10 years after primary right hemimandibulectomy. The patient had underwent 4 tumor surgeries in the jaw, 9 cycles of chemotherapy and 1.5 months of radiation. Recent evaluation found that the patient had multiple lung nodule in both lung and considered as metastases of ameloblastic carcinoma. No other metastases were found in other organs. The result of lung nodule resection followed by adjuvant chemotherapy could not be followed up.

\section{CASE REPORT}

A 46-year-old man experienced hemoptysis since 2 weeks before hospital admission. The patient had no other chest complains or symptoms. The patient had been diagnosed with mandibular ameloblastoma 10 years before and had undergone right hemimandibulectomy (Figure 1).

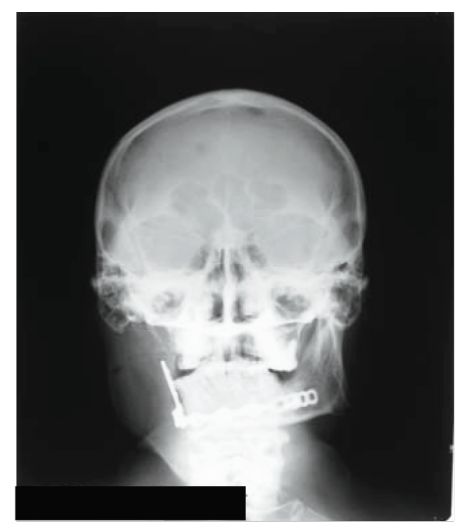

Figure 1. Skull x-ray showing mandibular plate placed after hemimandibulectomy 
At first, the tumor was considered benign. Unfortunately recurrency occurred and the patient underwent 3 more surgeries and a lung nodule was found on his chest x-ray. Then the patient received 9 cycles of chemotherapy and 1.5 months of radiation (beginning from the sixth cycle) and the tumor size was reduced. In early 2007 ( 2 years after chemotherapy), the patient went to a hospital because of hemoptysis and was referred to Cipto Mangunkusumo Hospital, Jakarta. Recent evaluation found that the patient had multiple lung nodules in both lungs (Figure 2 and 3 ).

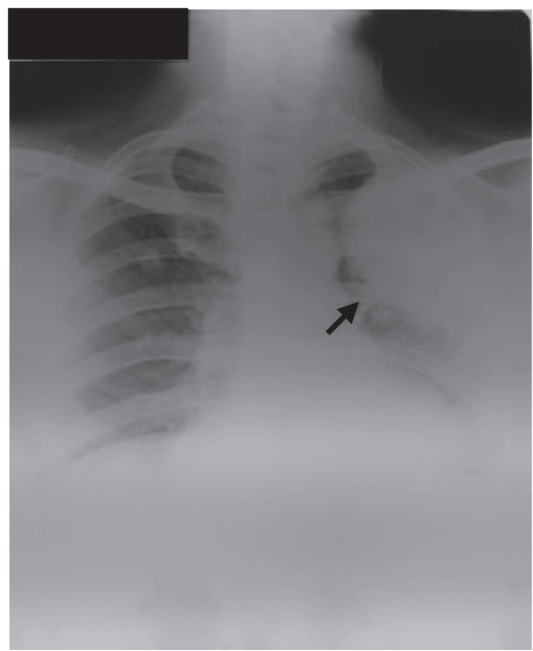

Figure 2. Chest $x$-ray showing a secondary mass in the left upper lobe

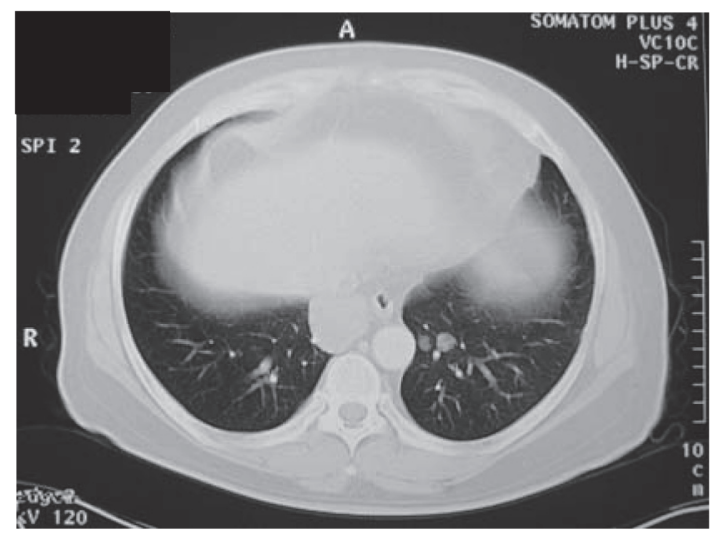

Figure 3. Chest CT-scan showing a secondary mass

Cytology specimens extracted from transthoracal biopsy aspiration showed tumor cells with pleomorphic nucleus and rough chromatin. Some tumor cells form groups indicating strong cohesion. In conclusion, cytological finding was consistent with carcinoma (Figure 4a-c).

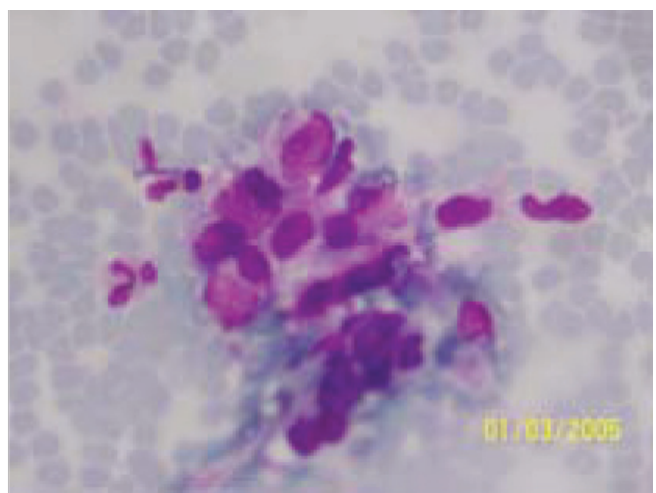

Figure $4 a$

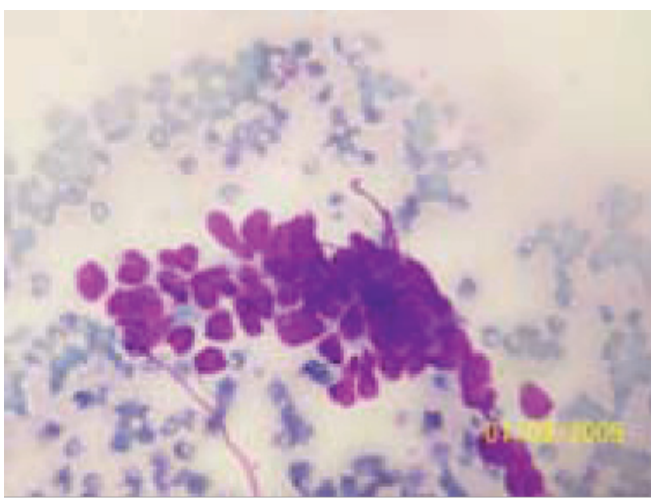

Figure $4 b$

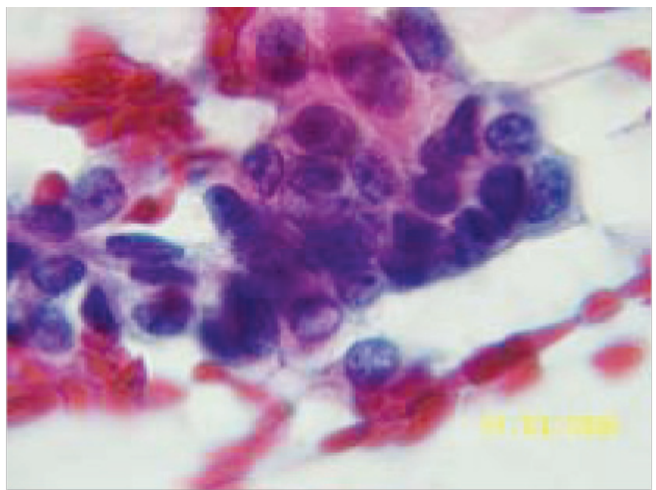

Figure $4 c$

Figure 4a-c. Histopathology slides of the secondary mass are in accordance to carcinoma

Unfortunately it was difficult to differentiate whether it was a primary tumor or metastases. Supported by other findings, we considered the lung nodule as metastases of ameloblastic carcinoma. No other metastases were found in other organs. 
After discussing this matter with the thoracic surgeon, pathologist, radiologist, oral surgeon, and hematologist, and supported by experts (pulmonologist from Mayo Clinic and Henry Ford Health System), we plan to resect the nodules on the left lung, followed by adjuvant chemotherapy using paclitaxel and carboplatin 3 weeks after the surgery. However, the patient was reluctant to continue the therapy, and did not return to our medical facility. Therefore, surgical and other therapeutic plans are postponed.

\section{DISCUSSION}

Ameloblastomas are benign but locally invasive odontogenic tumors of the jaws, representing $1 \%$ of all jaw tumors. ${ }^{1}$ Numerous histologic patterns are recognized by the World Health Organization (WHO), including follicular, plexiform, acanthomatous, granular cell, desmoplastic, basal cell, and extensively keratinized and papilliferous variants. The pathologic distinction of poorly differentiated or cytologically malignant ameloblastomas (ameloblastic carcinoma) from those that are well differentiated or histologically benign yet develop metastases (malignant from non malignant but metastasizing ameloblastoma) is not addressed by the 1992 WHO classification, but is recognized by others. ${ }^{4}$

The question of malignancy in ameloblastomas has been the subject of considerable discussion and controversy. There is little argument that an ameloblastoma that metastasizes is malignant, though the tumor shows benign histologic features. In other instances, an ameloblastoma is considered to be malignant on the basis of an aggressive clinical courses in the absence of metastasis. These lesions often show unusual atypical histologic features. A carcinoma that is derived from an ameloblastoma has been labeled by a variety of terms, including malignant ameloblastoma, ameloblastic carcinoma, metastatic ameloblastoma, and primary intra-alveolar epidermoid carcinoma. ${ }^{5}$

\section{WHO Classification}

In 1971, WHO classification of odontogenic carcinoma or "malignant ameloblastoma" refers to a neoplasm in which typical histologic features of ameloblastoma are seen in the primary tumor that are located in the jaw as well as in any associated metastasis deposits. ${ }^{5}$ Malignant ameloblastoma has been observed in patients whose age range is from 4 to 75 years (mean age 30 years).

For patients with documented metastases, the interval between the initial treatment of the ameloblastoma and first evidence of metastasis varies from 1 to 30 years. In nearly one third of the cases, metastases do not become apparent until 10 years after treatment of the primary tumor. Metastases from ameloblastoma are most often found in the lungs. These have sometimes been regarded as aspiration or implant metastases. However, the peripheral location of some of these lung metastases suggests that they must have occurred by blood or lymphatic routes rather than aspiration. ${ }^{6}$

Cervical lymph nodes are the second most common site for metastases of an ameloblastoma. ${ }^{6}$ However, a recent study found that $75 \%$ of metastases had been intrapleural or in hilar nodes and $15 \%$ in cervical lymph nodes or spine. ${ }^{2}$ Spreading to vertebrae, other bones, skin and viscera (eg. liver, spleen, kidney) has occasionally been confirmed. ${ }^{3,6}$

Many factors have been associated with the likelihood of developing metastases. Metastatic tumors occur usually in cases of long duration with multiple surgical procedures or radiation therapy. Extensive local disease and mandibular focus of the primary tumor also tend to be associated with development of metastases. ${ }^{1}$

The radiographic findings of malignant ameloblastoma may be essentially the same as those in typical nonmetastasizing ameloblastomas. However, ameloblastic carcinomas are often more aggressive with ill-defined margins and cortical destruction. ${ }^{6}$

\section{Ameloblastic carcinoma}

The term ameloblastic carcinoma in used to convey the presense of cytologic features of malignancy. The degree of differentiation in epithelial neoplasms is usually considered to be significant in predicting histologic behaviors of metastases. ${ }^{5}$ The term ameloblastic carcinoma designate lesion that exhibit histologic features of both ameloblastoma and carcinoma. ${ }^{7}$ It is a malignant epithelial proliferation that is associated with an ameloblastoma (carcinoma ex ameloblastoma) or histologically resembles an ameloblastoma (de novo ameloblastic carcinoma). Ameloblastic carcinoma subjectively demonstrates greater cytologic atipia and mitotic activity than ameloblastoma. These include an increased nuclear-to-cytoplasmic ratio, nuclear hyperchromatism, and the presence of mitosis. ${ }^{4,6}$ Necrotic tumor islands and areas of dystrophic calcification may also be present.

An ameloblastic carcinoma causes swelling of the jaw and frequently also causes pain and grows relatively 
rapidly. The mandible is most frequently involved. Root resorption, perforation of the buccal and lingual plates and extension into the soft tissue can follow. ${ }^{7}$ It is an aggressive neoplasma that is locally invasive (often extending out of bone to involve the infratemporal fossa, parapharyngeal space, the masticator space, or cervical soft tissue) and can spread to regional lymph nodes or distant sites, such as lung and bones. ${ }^{8}$ The tumor may metastasize and histologic features of malignancy may be found in either the primary tumor, the metastases or both. ${ }^{5}$ Malignant ameloblastoma with metastases to the lung may rarely associated with hypercalcemia. ${ }^{7}$

\section{Malignant ameloblastoma}

The term malignant ameloblastoma in confined to ameloblastoma that metastasizes despite an apparently typical benign histology in both the primary and metastatic lesions. Metastasizing ameloblastoma, ambiguously termed "malignant ameloblastoma", demonstrates the biologic behavior of a well-differentiated low-grade carcinoma. It is described as a tumor that shows histologic features of classic ameloblastoma in the gingival or jaw primary tumor and the metastatic deposits. ${ }^{8}$ The incidence of ameloblastic carcinoma is greater than that of malignant ameloblastoma by a ratio of $2: 1 .^{5}$

The cardinal feature of malignant ameloblastoma is metastatic spread. The histologic appereance of the primary and metastatic lesion is indistinguishable from benign ameloblastoma. In contrast, the primary and metastatic lesion of an ameloblastic carcinoma show histologically malignant epithelial features similar to an epidermoid carcinoma. ${ }^{9}$

\section{Management of ameloblastomas}

The treatment for metastatic ameloblastoma is controversial. The lack of a significant number of cases of ameloblastoma will probably prelude the development of an effective treatment strategies based on randomized protocol. Various studies have shown that ameloblastoma has responded unpredictably to radiation. ${ }^{1}$ Generally it has been reported to be radioresistant and, thus, radiotherapy has been reserved for palliation of patients with unresectable tumors. ${ }^{9}$

Surgery is the mainstay and optimal treatment for ameloblastoma and ameloblastic carcinomas. The optimal treatment for ameloblastic carcinoma is resection with wide margins. Recurrence rate of ameloblastoma are as high as $15 \%$ to $25 \%$ after wide resection and
$65 \%$ to $90 \%$ after less extensive operations such as curettage. However, the optimal surgical approach remains controversial. ${ }^{9}$ Significant resection with preservation of as much viable lung tissue as possible has been the treatment of choice, as this is the only way to offer a significant disease-free survival. ${ }^{1}$ In their 1993 case report, Sheppard et al as cited from Ciment and Ciment (2002), reported a patient who underwent eight thoracotomies before achieving disease-free status with no limitation of activities. ${ }^{1}$ Another study described a case of ameloblastoma with metastases to the lung and pleura, which exhibited response to paclitaxel and carboplatin. ${ }^{10}$

In conclusion, the case had ameloblastic carcinoma with lung metastases 10 years after an adequate treatment and the result of lung nodule resection followed by adjuvant chemotherapy could not be followed up.

\section{REFERENCES}

1. Ciment LM, Ciment AJ. Malignant ameloblastoma metastatic to the lungs 29 years after primary resection. A case report. Chest. 2002;121:1359-61.

2. Goldman KE. Mandibular cysts and odontogenic tumors. eMedicine. 2006 Mar 1 [cited 2008 Oct 9]. Avalaible from URL: http://www.emedicine.com/ent/topic681.htm

3. Jing W, Xuan M, Ling Y, Wu L, Liu L, Zheng X, et al. Odontogenic tumors: a retrospective study of 1642 cases in a Chinese population. Int $\mathrm{J}$ Oral Maxillofac Surg. 2007;36:20-5.

4. Zarbo RJ, Marunick MT, Johns R. Malignant ameloblastoma, spindle cell variant. 2003 Mar \{cited 2008 Oct 9]. Avalaible from URL: http://www.w3.org/TR/ xhtml1/DTD/xhtml1-transitional.dtd

5. Avon AL, McComb J, Clokie C. Ameloblastic carcinoma: case report and literature review. J Dent Assac. 2003;69(9):573-6.

6. Nevill BW, Doun DD, Allen C, Bouquot JE. Odontogenic cysts and tumors. In: Nevill BW, Dam DD, Allen C, Bouquot JE, editor. Oral \& Maxillofacial Pathology. $2^{\text {nd }}$ edition. New York: Saunders; 2002. p.611-20.

7. Cawson RA, Binnie WH, Barrett AW, Wright JM. Odontogenic tumours and tumor-like lesions. In: Cawson RA, Binnie WH, Barrett AW, Wright JM, editors. Oral disease; clinical and pathological correlations. $3^{\text {rd }}$ edition. London: Mosby; 2001. p.6.2-6.8.

8. Slater LJ. Odontogenic malignancies. Oral Maxillofacial Surg Clin N Am. 2004;16:409-24.

9. Phillip M, Morris CG, Werning JW, Mendenhall WM. Radiotherapy in the treatment of ameloblastoma and ameloblastic carcinoma. J HK Coll Radiol. 2005;8:157-61.

10. Grunwald V, Le Blanc S, Karstens JH. Metastatic malignant ameloblastoma responding to chemotherapy with paclitaxel and carboplatin. Ann Oncol. 2001;12:1489-91. 